\title{
Effect of temperature rise on microstructural evolution during high-pressure torsion
}

\section{Kaveh Edalati $^{1,2}$, Yuki Hashiguchi ${ }^{2}$, Pedro Henrique R. Pereira ${ }^{3}$, Zenji Horita ${ }^{1,2}$ and} Terence G. Langdon, ${ }^{3, *}$

${ }^{1}$ WPI, International Institute for Carbon-Neutral Energy Research (WPI-I2CNER), Kyushu University, Fukuoka 819-0395, Japan

${ }^{2}$ Department of Materials Science and Engineering, Faculty of Engineering, Kyushu University, Fukuoka 819-0395, Japan

${ }^{3}$ Materials Research Group, Faculty of Engineering and the Environment, University of Southampton, Southampton SO17 1BJ, UK

Dynamic recrystallization occurs at room temperature during high-pressure torsion (HPT) leading to the formation of ultrafine grains with high angles of misorientation. There are questions concerning whether dynamic recrystallization occurs due to the temperature rise during severe plastic deformation or due to the effect of lattice defects. In this study, the real temperature rise was measured by directly placing a thermocouple separately on disc samples of tin, aluminum, silver, copper and titanium. The measurements, which are consistent with finite element simulations, show that the temperature rise is of minor significance in initiating dynamic recrystallization. A relationship is developed to predict the temperature rise in HPT.

Keywords: dynamic recrystallization (DRX); high-pressure torsion (HPT); severe plastic deformation (SPD); temperature rise; ultrafine-grained (UFG) materials.

\footnotetext{
*Corresponding author: T.G. Langdon

E-mail: Langdon@ @oton.ac.uk
} 


\section{Introduction}

Severe plastic deformation (SPD) techniques [1,2] are widely used to produce ultrafine-grained (UFG) microstructures in metallic [3,4] and non-metallic [5,6] materials. Although the microstructure is refined significantly in the early stages of SPD, the grain size finally saturates to a steady-state condition at large strains [1-6]. The mechanism for the occurrence of a steady state has been discussed from the early discoveries of Bridgman using the high-pressure torsion (HPT) method [7,8] to recent reviews using different SPD techniques [1-4]. Dynamic recovery [9,10], dynamic recrystallization (DRX) [11,12] and grain boundary migration $[13,14]$ are some of the suggested mechanisms. Among these mechanisms, numerous experimental results provide clear evidence for the occurrence of DRX [12] and this not only controls the steady-state at large strains but also leads to the formation of high-angle grain boundaries in the early stages of straining [12].

The occurrence of DRX in SPD-processed materials at room temperature is widely attributed to the ultrahigh density of lattice defects [12-14]. However, it was suggested also that the microstructural evolution may be significantly influenced by heat generation and the consequent temperature rise $[11,15,16]$. It is anticipated that the HPT method, in which a small disc sample is rotated between two massive anvils [4,7], may exhibit a smaller temperature rise than other SPD methods since the cold massive anvils act as heat sinks for a small disc sample $[17,18]$. Therefore, processing by HPT should be promising for confirming the effect of temperature rise on microstructural evolution. However, there remain questions concerning the extent of the real temperature in HPT [16-20] because the imposed strain is substantially higher than in other SPD techniques [2].

A few limited studies have measured the temperature of HPT anvils and predicted the real temperature of the sample by using the finite element method (FEM) [18-20]. Nevertheless, there have been few attempts to measure the real temperatures of samples in HPT because of technical difficulties in placing a thermometer between the two rotating anvils under high pressure. Accordingly, the present research provides the first direct measurement of the temperature rise during HPT and this permits an examination of the significance of this temperature rise on microstructural evolution.

\section{Experimental materials and procedures}

High-purity Sn (99.9\%), Al (99.99\%), Ag (99.99\%), Cu (99.99999\%) and Ti (99.4\%) were selected as five model metals for this study. Discs of these metals with $10 \mathrm{~mm}$ diameter and $0.8 \mathrm{~mm}$ thickness were annealed for $1 \mathrm{~h}$ at temperatures of $453 \mathrm{~K}$ for $\mathrm{Sn}, 773 \mathrm{~K}$ for $\mathrm{Al}$, $803 \mathrm{~K}$ for $\mathrm{Ag}, 873 \mathrm{~K}$ for $\mathrm{Cu}$ and $1073 \mathrm{~K}$ for Ti to achieve average grain sizes of $\sim 590, \sim 620$, $>1000, \sim 310$ and $\sim 230 \mu \mathrm{m}$, respectively. The hardness levels after annealing were $7.6 \mathrm{Hv}$ for $\mathrm{Sn}, 22 \mathrm{Hv}$ for $\mathrm{Al}, 51 \mathrm{Hv}$ for $\mathrm{Ag}, 54 \mathrm{Hv}$ for $\mathrm{Cu}$ and $138 \mathrm{Hv}$ for Ti.

The disc samples were processed using a set of HPT anvils with $30 \mu \mathrm{m}$ surface roughness and the dimensions described in detail in earlier reports [17,20] except that all heat 
insulators were removed in this study to minimize the temperature rise. The samples were first processed by HPT at room temperature for $N=1 / 4-5$ turns under $1 \mathrm{GPa}$ for $\mathrm{Sn}$ to reduce the outflow of soft metal between the two HPT anvils, $6 \mathrm{GPa}$ for Al, $\mathrm{Ag}$ and $\mathrm{Cu}$ to minimize slippage between the sample and anvils [21] and $2 \mathrm{GPa}$ for Ti to avoid the formation of the $\omega$ phase [22,23]. The rotation speed was $0.5 \mathrm{rpm}$ for Ti and $1 \mathrm{rpm}$ for the other metals.

The samples after HPT processing were first polished and their Vickers microhardness measured from the disc center to the periphery along 4-8 radial directions with increments of 0.5 or $1 \mathrm{~mm}$. The hardness was measured using an indentation load of $10 \mathrm{~g}$ for $\mathrm{Sn}, 50 \mathrm{~g}$ for $\mathrm{Al}$ and $200 \mathrm{~g}$ for $\mathrm{Ag}, \mathrm{Cu}$ and Ti. The shear strain, $\gamma$, at each indentation point was calculated as [2]

$\gamma=\frac{2 \pi r N}{h}$

where, $r$ is the distance from the disc center, $N$ is the number of HPT turns and $h$ is the disc thickness.

The steady-state microstructures were examined by optical microscopy (OM) for Sn, electron back-scatter diffraction (EBSD) under $15 \mathrm{keV}$ for $\mathrm{Al}$ and $\mathrm{Ag}$ and transmission electron microscopy (TEM) under 200 or $300 \mathrm{keV}$ for $\mathrm{Cu}$ and Ti. Before microstructural examinations, the $\mathrm{Sn}$ samples were etched in a solution of $5 \% \mathrm{HCl}$ and $95 \% \mathrm{CH}_{3} \mathrm{OH}$ [24] and the other four metals were electro-polished in a solution of $15 \% \mathrm{HClO}_{4}, 15 \% \mathrm{C}_{3} \mathrm{H}_{5}(\mathrm{OH})_{3}$ and $70 \% \mathrm{CH}_{3} \mathrm{OH}$ for $\mathrm{Al}$ [25], $15 \% \mathrm{H}_{2} \mathrm{O}_{2}, 16 \% \mathrm{NH}_{3}$ and $69 \% \mathrm{H}_{2} \mathrm{O}$ for $\mathrm{Ag}$ [26], $15 \% \mathrm{HNO}_{3}, 15 \%$ $\mathrm{C}_{3} \mathrm{H}_{5}(\mathrm{OH})_{3}$ and $70 \% \mathrm{CH}_{3} \mathrm{OH}$ for $\mathrm{Cu}[25]$, and $5 \% \mathrm{HClO}_{4}, 25 \% \mathrm{C}_{3} \mathrm{H}_{3}\left(\mathrm{CH}_{2}\right)_{2} \mathrm{CH}_{2} \mathrm{OH}$ and $70 \%$ $\mathrm{CH}_{3} \mathrm{OH}$ for $\mathrm{Ti}[23]$.

The temperature rise during HPT processing was measured directly by placing a very small K-type thermocouple (chromel-alumel with $330 \mu \mathrm{m}$ wire diameter, 73-1523 K measurement range and $1.1 \mathrm{~K}$ special measurement accuracy) between the sample and the center of the upper anvil. It should be noted that the accuracy of the thermocouple was confirmed at room temperature by comparing its measurements with those measured by a precise thermometer. The lower anvil was then rotated with respect to the upper anvil using a rotation speed of $1 \mathrm{rpm}$ and a pressure of $2 \mathrm{GPa}$ for all selected metals until the thermocouple broke. In order to examine the reproducibility of results, temperature measurements were repeated at least two times except for $\mathrm{Ag}$ in which the thermocouple broke many times in a few seconds.

\section{Results}

Figure 1 shows the variation of hardness with shear strain for the five metals used in these experiments. Different hardness-strain behaviors are visible in Fig. 1 in agreement with earlier reports for Sn [24], Al [25,27,28], Cu [25] and Ti [23,29,30]. For Sn, the hardness decreases by $\sim 0.6 \mathrm{Hv}$ below the hardness level after annealing and saturates to a steady state at large strains. For $\mathrm{Al}$, the hardness increases with increasing shear strain but reaches a 
maximum and then decreases to a steady state. For $\mathrm{Ag}, \mathrm{Cu}$ and $\mathrm{Ti}$, the hardness increases with increasing strain and finally saturates to the steady-state values. The variations of hardness, $H v$, with shear strain are given by Eqs. (2-6) for $\mathrm{Sn}, \mathrm{Al}, \mathrm{Ag}, \mathrm{Cu}$ and $\mathrm{Ti}$, respectively.

$$
\begin{aligned}
& H v=7.6-0.6(1-\exp (-\gamma / 4)) \\
& H v=32+9 / \exp \left(-\left(\frac{\gamma-4}{5}\right)^{2}\right) \\
& H v=60+40(1-\exp (-\gamma / 1.5)) \\
& H v=90+52(1-\exp (-\gamma / 2)) \\
& H v=170+100(1-\exp (-\gamma / 8))
\end{aligned}
$$

Equations (2-6) show that a steady-state appears at large strains regardless of the different hardness-strain relationships as also discussed in other reports [24,27,31]. The steady-states microstructures shown in Fig. 2(a-e) contain grains with mainly high-angle boundaries (e.g., $85 \%$ of boundaries in $\mathrm{Al}$ and $73 \%$ of boundaries in $\mathrm{Ag}$ ) in good agreement with the earlier reports for Sn [24], Al [25,27,28], Ag [26], Cu [13,24,25] and Ti [1,23,29]. An examination shows that the average steady-state grain size decreases with increasing absolute melting temperature [24] and reaches $\sim 135 \mu \mathrm{m}$ for $\mathrm{Sn}, \sim 2.1 \mu \mathrm{m}$ for $\mathrm{Al}, \sim 380 \mathrm{~nm}$ for $\mathrm{Ag}, \sim 300$ $\mathrm{nm}$ for $\mathrm{Cu}$ and $\sim 200 \mathrm{~nm}$ for Ti. The formation of grains with high-angles of misorientation is a direct consequence of DRX [11-15].

Although the occurrence of DRX is expected at room temperature in Sn and Al, the temperature is low for the occurrence of $\mathrm{DRX}$ in $\mathrm{Ag}, \mathrm{Cu}$ and $\mathrm{Ti}$ because of their high melting temperatures. Therefore, it is necessary to determine whether the DRX occurs due to adiabatic heating $[11,15]$ or to the temperature rise during HPT processing. In practice, the HPT process consists of two stages with an initial compression and a subsequent rotation. The variation of temperature rise during the compression and rotation stages are shown in Figs. 3 and 4, respectively.

Figure 3 shows that the temperature rise during compression $(\sim 3-4 \mathrm{~K})$ is independent of the material hardness. The maximum temperature rise during compression ( $4 \mathrm{~K})$ occurs in Sn where Sn has the lowest hardness. Thus, the temperature rise for $\mathrm{Sn}$ is influenced by the significant outflow of this soft metal between the anvils during compression. It is concluded that the temperature rise during the compression stage of HPT is due mainly to the elastic deformation of the anvils [32] and only partly to the plastic deformation of the sample [33].

Figure 4 demonstrates four important points for the temperature rise during the rotation stage. First, the presence of excellent consistency between the two independent temperature measurements confirms the general reproducibility of the results. Second, since heat generation during HPT is proportional to the flow stress [17-19], the temperature rise 
increases with increasing material hardness. Third, the temperature rise is demonstrably too small (maximum $\sim 13 \mathrm{~K}$ for Ti) to promote the occurrence of DRX. Fourth, the variations in the temperature rise with time are essentially similar to the variations of hardness with shear strain in Fig. 1. For example, Sn shows a clear decrease in temperature after an initial abrupt temperature rise and this initial rise is due to the sudden outflow of material between the anvils. By contrast, $\mathrm{Al}$ shows a temperature peak and also a hardness peak whereas $\mathrm{Ag}, \mathrm{Cu}$ and Ti exhibit neither a hardness peak nor a temperature peak. The current results suggest that, although the temperature rise during HPT is relatively minor, the in situ temperature measurements can provide important information regarding the dynamic behavior of the material as attempted earlier [20] in examining phase transformations during HPT. It should be noted that the current temperature rises were measured on the upper surface of the disc at the central region, while the temperature at the outer region of the disc may be slightly higher (negligible difference across the thickness and a few Kelvins difference along the radius based on the FEM simulations [17]).

\section{Discussion}

Using the data achieved in this study, it is important to develop a model to predict the temperature rise during HPT. The temperature-time curves shown in Fig. 4 are basically similar to those for unsteady-state heat conduction phenomena [34] which are generally expressed by the relationship

$$
\Delta T=\Delta T_{S S}(1-\exp (-t / c))
$$

where $\Delta T$ is the temperature rise at a time of $t, \Delta T_{S S}$ is the steady-state temperature rise and $c$ is a time constant depending on the thermal properties and size of the sample and anvils. The steady-state temperature rise during HPT is directly proportional to the heat flux, $\phi$, and this flux is proportional to the flow stress, $\sigma$, and the rotation speed, $\omega$, so that [17]

$$
\phi=\sigma r \omega
$$

The origin of Eq. (8) is discussed in more detail in the Appendix.

Therefore, it follows that Eq. (7) can be summarized as

$$
\Delta T=a \sigma \omega(1-\exp (-t / c))
$$

where $a$ is a constant dependent upon the thermal properties and sizes of the sample, anvils, heat insulators and other metallic parts connected to the anvils. Since the size of the sample is much smaller than the size of the anvils, the effect of the thermal properties of the sample on $a$ and $c$ may be reasonably ignored so that the main effect of the sample on the temperature rise is through the heat flux and the flow stress. It should be noted that this simplification is no longer valid when materials with low thermal conductivity, such as ceramics, are processed by HPT $[5,6]$. Since the same tool steel anvils were used in this study for processing of five 
different metals, it is possible to find the values of $a$ and $c$ by directly fitting the experimental data. If the flow stress is estimated as $H v / 3$ using Eqs. (2-6), and the flow stress at $3.53 \mathrm{~mm}$ from the disc center is taken as the average flow stress in a disc with a diameter of $2 R=10$ $\mathrm{mm}$ where $3.53 \mathrm{~mm}$ is achieved by mathematical integration as $r=R / \sqrt{2}$, the following equation is achieved:

$$
\Delta T=0.017 \sigma \omega(1-\exp (-t / 2))
$$

where $\Delta T$ is in $\mathrm{K}, \sigma$ is in $\mathrm{MPa}, \omega$ is in rpm and $t$ is in s. Figure 5 compares the experimental data with those achieved using Eq. (10) and it is readily apparent that the temperature rise for all experimental metals may be predicted using a single equation. Thus, the deviations observed for $\mathrm{Sn}$ and $\mathrm{Al}$ are due to the significant outflow of these soft metals at the onset of rotation which produces a sudden temperature increase. Furthermore, Eq. (10) shows that the temperature rise during HPT is of minor significance in influencing the microstructure [4] and phase transformations [35] although small temperature rises may influence the formation of metastable phases when the dynamic phase-transition temperatures are close to the ambient temperature [23,29].

As noted earlier, a few limited studies have measured the temperature of the HPT anvils and predicted the real temperature rise in the sample by using FEM simulations [18-20]. Figure 6 summarizes the data reported earlier [17] for the experimental temperature rise in the HPT anvils (measured by placing a thermocouple in the upper anvil at $2 \mathrm{~mm}$ above the sample) and the calculated temperature rise in the sample (calculated by FEM simulations for $\mathrm{Al}, \mathrm{Cu}$ and $\mathrm{Fe}$ discs). The simulation results in Fig. 6 are in good agreement with the direct temperature measurements in the current study (maximum $\sim 14 \mathrm{~K}$ for $\mathrm{Fe}$ which has a hardness-strain behavior similar to Ti). It is concluded that, although a few studies suggested the occurrence of a high temperature rise during HPT processing $[16,23,36]$, the current study in connection with earlier data [17] confirms that the macroscopic temperature rise is of only minor significance in influencing the microstructure and the occurrence of DRX. It should be noted that this conclusion may be changed if, for example, the sample size is large, the HPT anvils are small or the HPT anvils are surrounded by heat insulators or connected to small metallic plates which act as heat sinks.

In practice, the small temperature rises measured during HPT processing confirm that the occurrence of DRX at large strains should be mainly due to the formation of a large fraction of lattice defects such as vacancies where their concentration is sometimes comparable to the concentration of vacancies at the melting temperature [37,38], dislocations which can have a density as high as $\sim 10^{15}-10^{16} \mathrm{~cm}^{-2}[10,33]$, subgrain boundaries which are distributed at nanometer to submicrometer distances $[4,12]$ and high-energy non-equilibrium grain boundaries which separate ultrafine grains [1]. The presence of large fractions of these lattice defects enhances the internal energy of the system even at room temperature and leads to the occurrence of DRX and a subsequent reduction in the total energy of the system. 


\section{Conclusions}

This report describes the first experimental investigation of the real temperature of disc samples processed by HPT at room temperature. It is found that the temperature rises are relatively minor when compared with the melting temperatures of the processed metals. It is concluded that the microstructural evolutions occurring during HPT processing are not significantly influenced by the temperature rise. On the contrary, the formation of high-angle grain boundaries through DRX is due to the presence of large volumes of lattice defects.

\section{Acknowledgments}

We thank Prof. Alexander P. Zhilyaev of Russian Academy of Sciences for insightful discussion. This study was supported in part by Grant-in-Aids for Scientific Research from the MEXT, Japan (No. 16H04539 and No. 26220909). Two of the authors were supported by the European Research Council under Grant Agreement No. 267464-SPDMETALS (PHRP and TGL). The HPT process was carried out in the International Research Center on Giant Straining for Advanced Materials (IRC-GSAM) at Kyushu University.

\section{Appendix}

When a disc sample is processed by HPT, the temperature increases because of heat generation due to three main effects: (1) plastic work, (2) pressure-induced phenomena such as a phase transition, internal friction increase and thermoelectric effect, and (3) frictional heat generation [17]. When the processing pressure is high and the surfaces of two anvils are sufficiently rough, the effect of frictional heat generation can be neglected because no slippage occurs between the sample and the anvils [21]. The pressure-induced heat generation can be also neglected if there is no phase transition. Therefore, the main source of temperature rise during the HPT process can be attributed to the plastic work. The magnitude of the plastic work per unit volume is proportional to the flow stress, $\sigma$, and the plastic strain, $\varepsilon$, through the following equation [39].

$U=\sigma \varepsilon$

The plastic strain in HPT is almost uniform across the disc thickness and it is directly proportional to the distance from the disc center, as shown in Eq. (1). If it is assumed that an HPT disc sample contains numerous ring-shaped heat sources with mean radius of $r$, incremental widths of $w$ and thicknesses of $h$, the generated heat flux, $\phi$, in each source is given by the following relationship:

$\phi=\frac{\beta \sigma \dot{\varepsilon} V}{A}=\frac{\beta \sigma \dot{\varepsilon}(2 \pi r w h)}{2 \pi r w}=\beta \sigma\left(\frac{r \omega}{h}\right) h$

In this equation, $\beta$ is the fraction of plastic work which is converted into heat, $\dot{\varepsilon}$ is the strain 
rate which is given by $r \omega / h$ where $\omega$ is the rotation speed, $V$ is the volume and $A$ is the horizontal area of the element. Assuming reasonably that the plastic work is fully converted to heat (i.e., $\beta=1$ ), $\phi$ is given as [17]

$\phi=\sigma \cdot r \omega$

Therefore, the heat flux is directly proportional to the distance from the disc center, the rotation speed and the hardness of the material and it is independent of the disc thickness. 


\section{References}

[1] R.Z. Valiev, R.K. Islamgaliev, I.V. Alexandrov, Bulk nanostructured materials from severe plastic deformation, Prog. Mater. Sci. 45 (2000) 103-189.

[2] R.Z. Valiev, Y. Estrin, Z. Horita, T.G. Langdon, M.J. Zehetbauer, Y.T. Zhu, Producing bulk ultrafine-grained materials by severe plastic deformation, JOM 58(4) (2006) 33-39.

[3] R.Z. Valiev, T.G. Langdon, Principles of equal-channel angular pressing as a processing tool for grain refinement, Prog. Mater. Sci. 51 (2006) 881-981.

[4] A.P. Zhilyaev, T.G. Langdon, Using high-pressure torsion for metal processing: fundamentals and applications, Prog. Mater. Sci. 53 (2008) 893-979.

[5] K. Edalati, Z. Horita, A review on high-pressure torsion (HPT) from 1935 to 1988, Mater. Sci. Eng A 652 (2016) 325-352.

[6] H. Razavi-Khosroshahi, K. Edalati, M. Arita, Z. Horita, M. Fuji, Plastic strain and grain size effect on high-pressure phase transformations in nanostructured $\mathrm{TiO}_{2}$ ceramics, Scripta Mater. 124 (2016) 59-62.

[7] P.W. Bridgman, Effects of high shearing stress combined with high hydrostatic pressure, Phys. Rev. 48 (1935) 825-847.

[8] P.W. Bridgman, Flow phenomena in heavily stressed metals, J. Appl. Phys. 8 (1937) 328-336.

[9] F.A. Mohamed, A dislocation model for the minimum grain size obtainable by milling, Acta Mater. 51 (2003) 4107-4119.

[10] M.J. Starink, X.C. Cheng, S. Yang, Hardening of pure metals by high-pressure torsion: A physically based model employing volume-averaged defect evolutions, Acta Mater. 61 (2013) 183-192.

[11] A.P. Zhilyaev, S. Swaminathan, A.I. Pshenichnyuk, T.G. Langdon, T.R. McNelly, Adiabatic heating and the saturation of grain refinement during SPD of metals and alloys: experimental assessment and computer modeling, J. Mater. Sci. 48 (2013) 4626-4636.

[12] T. Sakai, A. Belyakov, R. Kaibyshev, H. Miura, J.J. Jonas, Dynamic and post-dynamic recrystallization under hot, cold and severe plastic deformation conditions, Prog. Mater. Sci. 60 (2014) 130-207.

[13] A. Mishra, B.K. Kad, F. Gregori, M.A. Meyers, Microstructural evolution in copper subjected to severe plastic deformation: Experiments and analysis, Acta Mater. 55 (2007) 13-28.

[14] R. Pippan, S. Scheriau, A. Taylor, M. Hafok, A. Hohenwarter, A. Bachmaier, Saturation of fragmentation during severe plastic deformation, Annu. Rev. Mater. Res. 40 (2010) 319-343.

[15] Q. Wei, L. Kecskes, T. Jiao, K.T. Hartwig, K.T. Ramesh, E. Ma, Adiabatic shear banding in ultrafine-grained Fe processed by severe plastic deformation, Acta Mater. 52 (2004) 1859-1869. 
[16] S. Hober, Z. Kovacs, A. Revesz, Estimation of heat production during high pressure torsion of Cu-based metallic glass, J. Alloys Compd. 495 (2010) 352-355.

[17] K. Edalati, R. Miresmaeili, Z. Horita, H. Kanayama, R. Pippan, Significance of temperature increase in processing by high-pressure torsion, Mater. Sci. Eng. A 528 (2011) 7301-7305.

[18] R.B. Figueiredo, P.H.R. Pereira, M.T.P. Aguilar, P.R. Cetlin, T.G. Langdon, Using finite element modeling to examine the temperature distribution in quasi-constrained high-pressure torsion, Acta Mater. 60 (2012) 3190-3198.

[19] P.H.R. Pereira, R.B. Figueiredo, Y. Huang, P.R. Cetlin, T.G. Langdon, Modeling the temperature rise in high-pressure torsion, Mater. Sci. Eng. A 593 (2014) 185-188.

[20] K. Edalati, D.J. Lee, T. Nagaoka, M. Arita, H.S. Kim, Z. Horita, R. Pippan, Real hydrostatic pressure in high-pressure torsion measured by bismuth phase transformations and FEM simulations, Mater. Trans. 57 (2016) 533-538.

[21] K. Edalati, Z. Horita, T.G. Langdon, The significance of slippage in processing by high-pressure torsion, Scripta Mater. 60 (2009) 9-12.

[22] Y. Ivanisenko, A. Kilmametov, H. Rosner, R.Z. Valiev, Evidence of $\alpha \rightarrow \omega$ phase transition in titanium after high pressure torsion, Int. J. Mater. Res. 99 (2008) 36-41.

[23] K. Edalati, E. Matsubara, Z. Horita, Processing pure Ti by high-pressure torsion in wide ranges of pressures and strain, Metall. Mater. Trans. A 40 (2009) 2079-2086.

[24] K. Edalati, Z. Horita, Significance of homologous temperature in softening behavior and grain size of pure metals processed by high-pressure torsion, Mater. Sci. Eng. A 528 (2011) 7514-7523.

[25] K. Edalati, J.M. Cubero-Sesin, A. Alhamidi, I.F. Mohamed, Z. Horita, Influence of severe plastic deformation at cryogenic temperature on grain refinement and softening of pure metals: Investigation using high-pressure torsion, Mater. Sci. Eng. A 613 (2014) 103-110.

[26] H. Matsunaga, Z. Horita, Softening and microstructural coarsening without twin formation in FCC metals with low stacking fault energy after processing by high-pressure torsion, Mater. Trans. 50 (2009) 1633-1637.

[27] C. Xu, Z. Horita, T.G. Langdon, The evolution of homogeneity in processing by high-pressure torsion, Acta Mater. 55 (2007) 203-212.

[28] M. Kawasaki, R.B. Figueiredo, T.G. Langdon, An investigation of hardness homogeneity throughout disks processed by high-pressure torsion, Acta Mater. 59 (2011) 308-316.

[29] H. Shahmir, T.G. Langdon, Characteristics of the allotropic phase transformation in titanium processed by high-pressure torsion using different rotation speeds, Mater. Sci. Eng. A 667 (2016) 293-299.

[30] H. Shahmir, T.G. Langdon, An evaluation of the hexagonal close-packed to face-centered cubic phase transformation in a Ti-6Al-4V alloy during high-pressure 
torsion, Mater. Sci. Eng. A 704 (2017) 212-217.

[31] M. Kawasaki, Different models of hardness evolution in ultrafine-grained materials processed by high-pressure torsion, J. Mater. Sci. 49 (2014) 18-34.

[32] P.H.R. Pereira, R.B. Figueiredo, P.R. Cetlin, T.G. Langdon, An examination of the elastic distortions of anvils in high-pressure torsion, Mater. Sci. Eng. A 631 (2015) 201-208.

[33] D.J. Lee, E.Y. Yoon, S.H. Lee, S.Y. Kang, H.S. Kim, Finite element analysis for compression behavior of high pressure torsion processing, Rev. Adv. Mater. Sci. 31 (2012) 25-30.

[34] H.S. Carslaw, J.C. Jaeger, Conduction of Heat in Solids, second ed., Clarendon Press, Oxford, 1986.

[35] X. Sauvage, M.Y. Murashkin, B.B. Straumal, E.V. Bobruk, R.Z. Valiev, Ultrafine grained structures resulting from SPD-induced phase transformation in Al- $\mathrm{Zn}$ alloys, Adv. Eng. Mater. 17 (2015) 1821-1827.

[36] A.P. Zhilyaev, J.M. Garcia-Infanta, F. Carreno, T.G. Langdon, O.A. Ruano, Particle and grain growth in an Al-Si alloy during high-pressure torsion, Scripta Mater. 57 (2007) 763-765.

[37] B. Oberdorfer, B. Lorenzoni, K. Unger, W. Sprengel, M. Zehetbauer, R. Pippan, R. Wurschum, Absolute concentration of free volume-type defects in ultrafine-grained $\mathrm{Fe}$ prepared by high-pressure torsion, Scripta Mater. 63 (2010) 452-455.

[38] J. Cizek, M. Janecek, O. Srba, R. Kuzel, Z. Barnovska, I. Prochazka, S. Dobatkin, Evolution of defects in copper deformed by high-pressure torsion, Acta Mater. 59 (2011) 2322-2329.

[39] G.E. Dieter, Mechanical Metallurgy, third ed., McGraw-Hill, New York, 1976. 


\section{Figure Captions}

Figure 1. Hardness-strain behavior of $\mathrm{Sn}, \mathrm{Al}, \mathrm{Ag}, \mathrm{Cu}$ and Ti processed by HPT.

Figure 2. Steady-state microstructures of $\mathrm{Sn}, \mathrm{Al}, \mathrm{Ag}, \mathrm{Cu}$ and $\mathrm{Ti}$ processed by HPT, where (a) is an OM micrograph, $(b, c)$ are EBSD crystal orientation maps and (d, e) are TEM dark-field images.

Figure 3. (a) Temperature rise against time during compression of $\mathrm{Sn}, \mathrm{Al}, \mathrm{Ag}, \mathrm{Cu}$ and $\mathrm{Ti}$ under pressure of $2 \mathrm{GPa}$, and (b) schematic set up of sample and thermocouple for temperature measurement.

Figure 4. Temperature rise against time during HPT processing of $\mathrm{Sn}, \mathrm{Al}, \mathrm{Cu}$ and $\mathrm{Ti}$ under pressure of $2 \mathrm{GPa}$. The measurements were repeated two times until the thermocouples broke.

Figure 5. Temperature rise against time measured experimentally during HPT processing and calculated using Eq. (10) for $\mathrm{Sn}, \mathrm{Al}, \mathrm{Ag}, \mathrm{Cu}$ and Ti samples.

Figure 6. Temperature rise against time in HPT anvil measured at $2 \mathrm{~mm}$ above disc sample using thermocouple and at sample edge calculated by FEM. Data taken from Ref. [17]. 


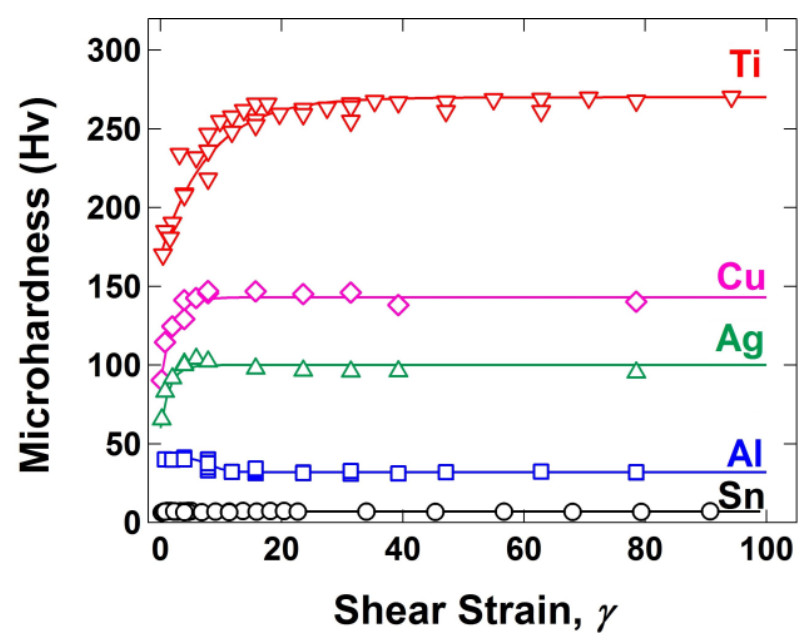

Figure 1. Hardness-strain behavior of $\mathrm{Sn}, \mathrm{Al}, \mathrm{Ag}, \mathrm{Cu}$ and $\mathrm{Ti}$ processed by HPT. 

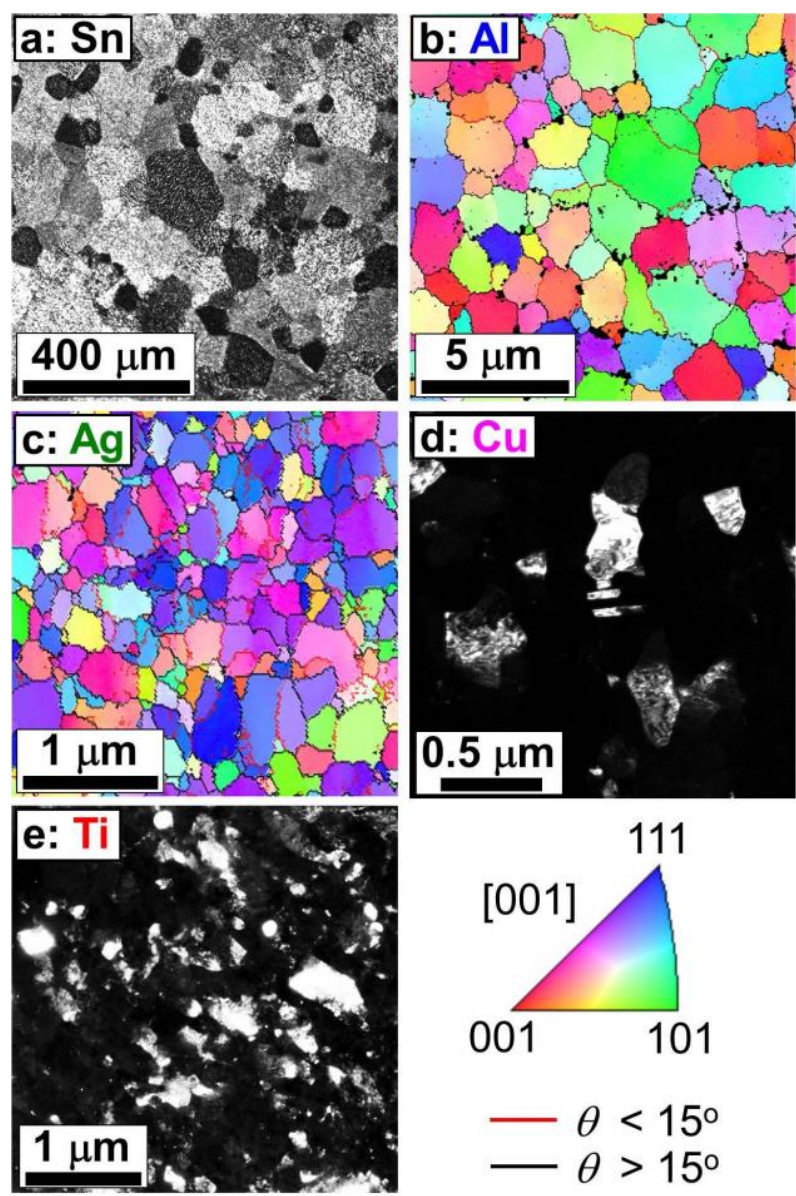

Figure 2. Steady-state microstructures of $\mathrm{Sn}, \mathrm{Al}, \mathrm{Ag}, \mathrm{Cu}$ and $\mathrm{Ti}$ processed by HPT, where (a) is an OM micrograph, $(b, c)$ are EBSD crystal orientation maps and (d, e) are TEM dark-field images. 


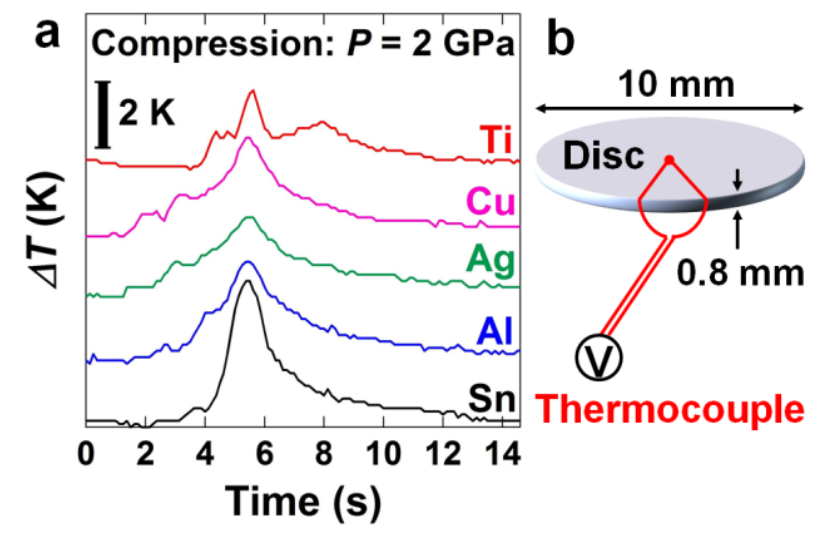

Figure 3. (a) Temperature rise against time during compression of $\mathrm{Sn}, \mathrm{Al}, \mathrm{Ag}, \mathrm{Cu}$ and Ti under pressure of $2 \mathrm{GPa}$, and (b) schematic set up of sample and thermocouple for temperature measurement. 

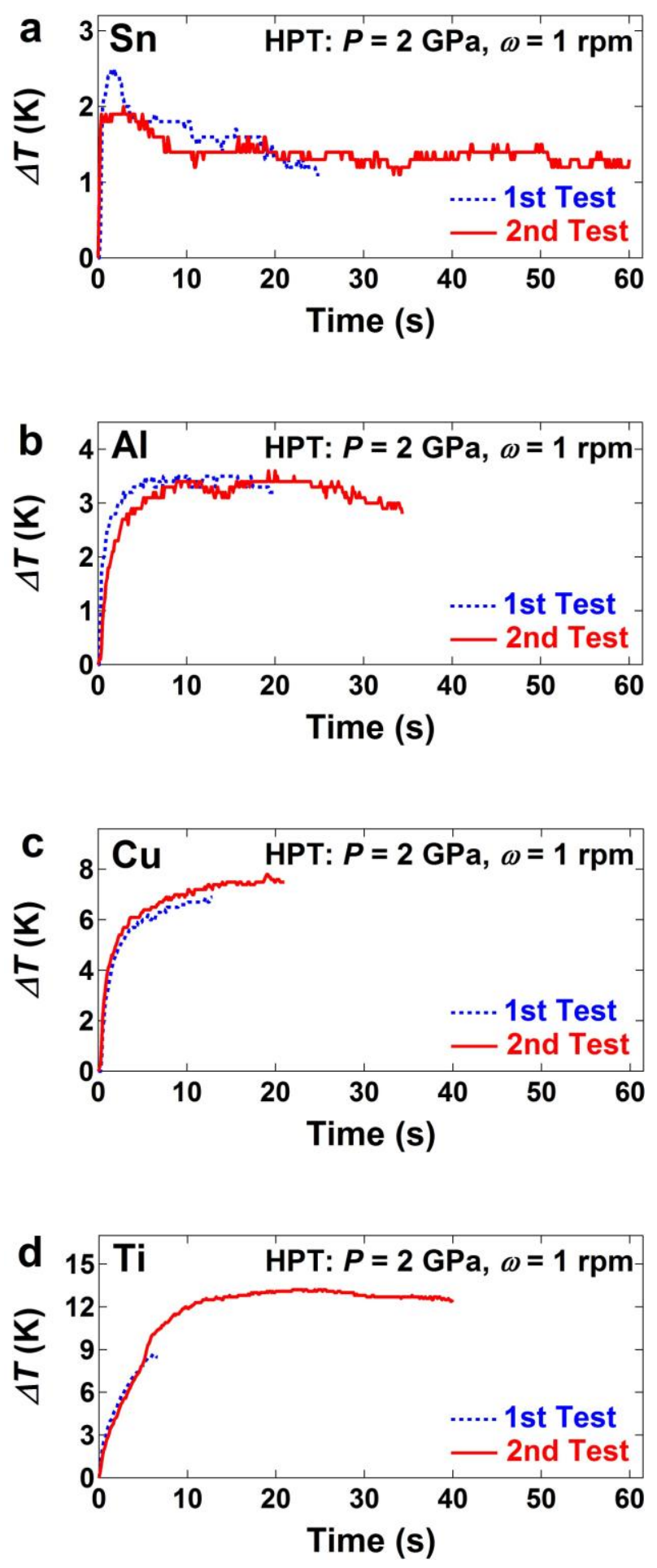

Figure 4. Temperature rise against time during HPT processing of $\mathrm{Sn}, \mathrm{Al}, \mathrm{Cu}$ and $\mathrm{Ti}$ under pressure of $2 \mathrm{GPa}$. The measurements were repeated two times until the thermocouples broke. 


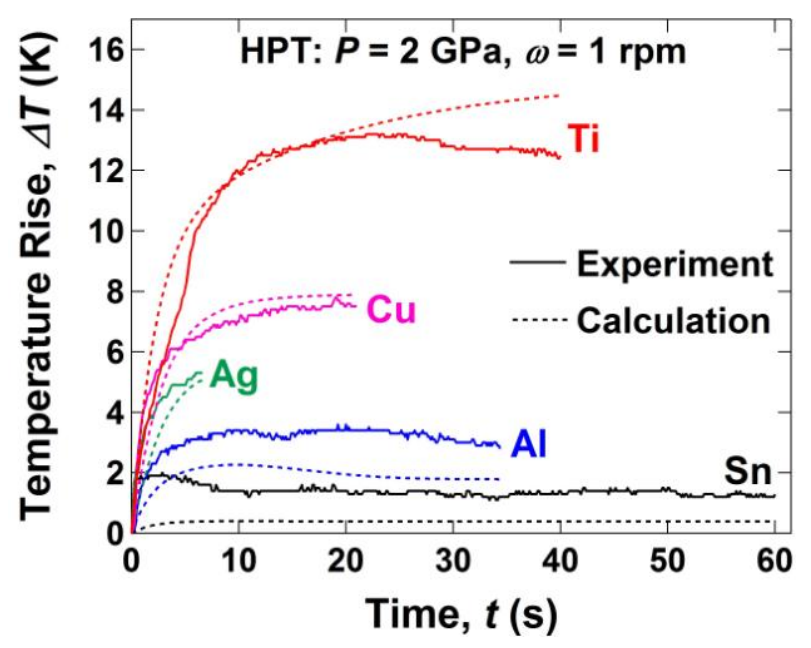

Figure 5. Temperature rise against time measured experimentally during HPT processing and calculated using Eq. (10) for $\mathrm{Sn}, \mathrm{Al}, \mathrm{Ag}, \mathrm{Cu}$ and Ti samples. 


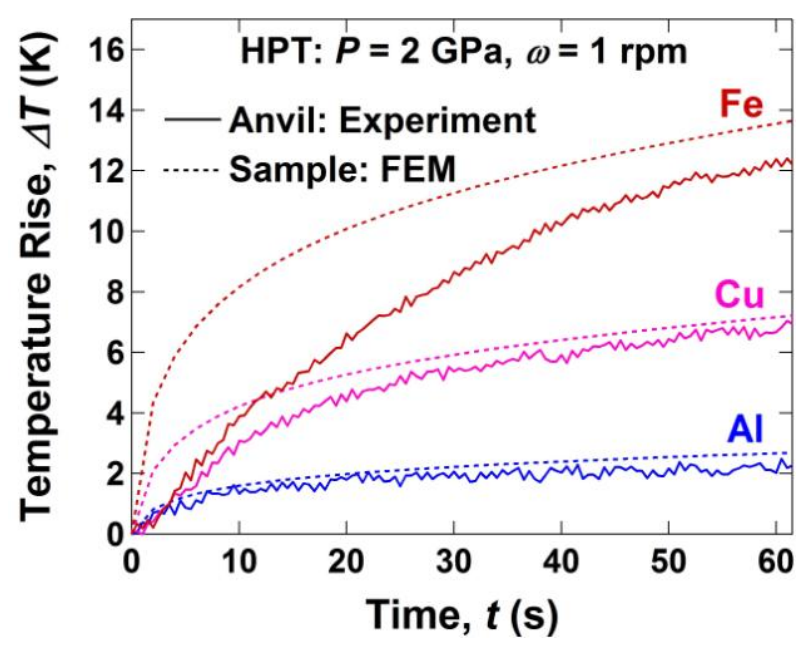

Figure 6. Temperature rise against time in HPT anvil measured at $2 \mathrm{~mm}$ above disc sample using thermocouple and at sample edge calculated by FEM. Data taken from [17]. 